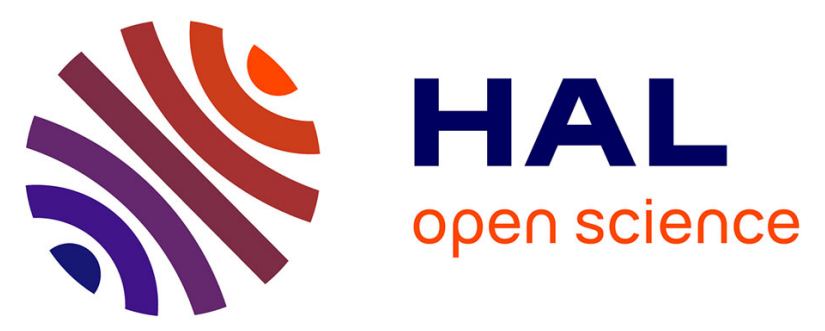

\title{
Detection and clinical relevance of early disseminated breast cancer cells depend on their cytokeratin expression pattern
}

Katharina E. Effenberger, Elin Borgen, Christine Zu Eulenburg, Kai

Bartkowiak, Andrea Grosser, Marit Synnestvedt, Rolf Kaaresen, Burkhard Brandt, Jahn M. Nesland, Klaus Pantel, et al.

\section{To cite this version:}

Katharina E. Effenberger, Elin Borgen, Christine Zu Eulenburg, Kai Bartkowiak, Andrea Grosser, et al.. Detection and clinical relevance of early disseminated breast cancer cells depend on their cytokeratin expression pattern. Breast Cancer Research and Treatment, 2010, 125 (3), pp.729-738. 10.1007/s10549-010-0911-2 . hal-00561317

\section{HAL Id: hal-00561317 https://hal.science/hal-00561317}

Submitted on 1 Feb 2011

HAL is a multi-disciplinary open access archive for the deposit and dissemination of scientific research documents, whether they are published or not. The documents may come from teaching and research institutions in France or abroad, or from public or private research centers.
L'archive ouverte pluridisciplinaire HAL, est destinée au dépôt et à la diffusion de documents scientifiques de niveau recherche, publiés ou non, émanant des établissements d'enseignement et de recherche français ou étrangers, des laboratoires publics ou privés. 


\title{
Detection and clinical relevance of early disseminated breast cancer cells depend on their cytokeratin expression pattern
}

\author{
Katharina E Effenberger ${ }^{1}$, Elin Borgen ${ }^{2 a}$, Christine zu Eulenburg ${ }^{3}$, Kai \\ Bartkowiak $^{1}$, Andrea Grosser ${ }^{3}$, Marit Synnestvedt ${ }^{5}$, Rolf Kaaresen ${ }^{4}$, Burkhard \\ Brandt $^{1}$, Jahn M Nesland ${ }^{2 b}$, Klaus Pantel ${ }^{1}$ and Bjorn Naume ${ }^{5}$. \\ ${ }^{1}$ Institute of Tumor Biology, University Medical Center Hamburg-Eppendorf, \\ Hamburg, Germany; ${ }^{2 a}$ Department of Pathology, The Norwegian Radium \\ Hospital, Oslo University Hospital, University of Oslo, Norway; ${ }^{2 b}$ Department of \\ Pathology, Faculty Division, The Norwegian Radium Hospital, Medical Faculty, \\ University of Oslo, Norway; ${ }^{3}$ Department of Medical Biometry and Epidemiology, \\ University Medical Center Hamburg-Eppendorf, Hamburg, Germany; \\ ${ }^{4}$ Department of Surgery, Ulleval Hospital, Oslo University Hospital, Oslo, \\ Norway; ${ }^{5}$ Department of Oncology, The Norwegian Radium Hospital, Oslo \\ University Hospital, University of Oslo, Oslo, Norway.
}

Corresponding author: Klaus Pantel, Institute of Tumor Biology, University Medical Center Hamburg-Eppendorf, Martinistr. 52 D-20246 Hamburg, Germany. Phone: +4940-741053503; Fax: +4940-74105-5379; E-mail: pantel@uke.de. 
Abstract

Background: The factors determining the clinical relevance of disseminated tumor cells (DTC) in breast cancer patients are largely unknown. Here we compared the specificity and clinical performance of two antibodies frequently used for DTC detection.

Methods: Reactivities of antibodies A45-B/B3 (A45) and AE1/AE3 (AE) for selected cytokeratins (CK) were assessed by 2-DE western blot analysis. Using these antibodies bone marrow aspirates from 391 breast cancer patients $\left(\mathrm{M}_{0}, \mathrm{pT} 1-3, \mathrm{pN} 0-3\right)$ were screened for the presence of DTC. To obtain prognostic information, patients were followed up over a median of 83 months for time to relapse and 99 months for time to death.

Results: Among the analyzed CK, AE detected CK5, CK7, CK8, and CK19, whereas A45 recognized CK7 and CK18. In total, 24 of 391 patients (6.1\%) were DTC-positive for A45, and 41 (10.5\%) for AE. Although concordance between the two antibodies was $84.4 \%$, overlap among positive cases was only 3.2\%. DTC-positivity with AE and A45 was more frequent in patients of higher nodal status ( $\mathrm{p}=0.019$ and $\mathrm{p}=0.036$, respectively). Nearly all patients with $\mathrm{A} 45$-positive DTC had hormone receptor-positive tumors (23/24), while detection of AE-positive DTC was more frequent among hormone receptor negative patients $(\mathrm{p}=0.006)$. Survival analyses of all patients revealed shorter distant disease-free survival $(\mathrm{p}=0.039)$ for patients with A45-positive DTC, whereas the prognostic relevance of AE-positive DTC was restricted to node positive patients.

Conclusions: The clinical utility of immunocytochemical DTC detection depends on the anti-CK antibody used, which may reflect the complex CK composition of DTC.

Keywords: anti-cytokeratin antibodies; bone marrow; breast cancer; disseminated tumor cells; micrometastasis. 


\section{Introduction}

Metastasis is the main cause of cancer-related death and the skeleton is the most prominent site of metastatic relapse in breast cancer. The presence of disseminated tumor cells (DTC) in bone marrow of breast cancer patients serves as a surrogate marker for early micrometastatic spread [1]. Moreover, the recent data on the effect of bisphosphonate treatment on prevention of metastatic relapse in and outside bone [2] supports the assumption that bone marrow might be a reservoir for DTC from where they can disseminate into other organs [3, 4]. It can even be speculated that DTC in bone marrow may use the same niches as hematopoietic stem cells. This might explain the observation that DTC can be comobilized with hematopoietic stem cells following induction treatment before high-dose chemotherapy [5]. Moreover, Bidard et al. [6] recently reported a strong correlation between the presence of DTC in bone marrow and local relapse in breast cancer, suggesting that DTC may re-circulate from the bone marrow back to the primary site of tumor growth [3]. This provocative hypothesis is also supported by recent experimental data of Joan Massague's group obtained in mouse models [7]. Thus, despite the recent focus on the detection of tumor cells circulating in the peripheral blood, screening of bone marrow for DTC might still have substantial future applications with regard to stratification and monitoring of therapies affecting the interaction between metastatic cells and bone marrow environment.

However, the reliability of current DTC detection assays remains still under debate. One main reason for discrepant findings might be the heterogeneity in biological properties of DTC [4] which may affect their detection by specific antibodies or mRNA target transcripts. Most of the DTC detection methods are based on immunocytochemical staining with antibodies directed against cytokeratins (CK) [8-10]. Numerous "broad spectrum" CK antibodies recognizing a common epitope on various CK proteins exist. However, the specificities of these antibodies differ considerably and are not well defined. CK constitute the largest intermediate filament protein subgroup and represent a multigene family with more than 20 different types of polypeptides that are divided into acidic type I (CK9-CK20) and basic type II (CK1-CK8) keratins [11]. CK form the cytoskeleton of epithelial cells and their main function is to maintain the epithelial 
cell integrity. The most commonly used broad spectrum anti-CK antibodies, A45$\mathrm{B} / \mathrm{B} 3$ and $\mathrm{AE} 1 / \mathrm{AE} 3$ (hereafter referred to as "A45" and "AE"), have been shown to be specific for DTC detection as shown by analysis of large cohorts of noncancer control patients [12-15]. Although both, A45 and AE1/AE3, are broad spectrum anti-CK monoclonal antibodies, difference in the antibody epitope binding might potentially give different DTC results in individual cases because CK expression varies considerably in breast cancer cells during tumor progression. $[16,17]$ Individual CK proteins (e.g. CK18) can be down-regulated as a consequence of an epithelial-mesenchymal transition [18], an important process recently linked to cancer stem cell behavior [4].

Here we compared the epitope specificity, and in particular the clinical utility of monoclonal anti-CK antibodies A45 and AE for DTC detection in bone marrow of patients with primary breast cancer. Our results suggest that both antibodies recognize separate biological subsets of DTC probably expressing differential patterns of CK proteins, and these cells appear to be relevant in different stages of breast cancer progression. 


\section{Material and Methods}

\section{Patients}

Women with early breast cancer were treated at five hospitals in the Oslo region between 1995 and 1998. The patients within this study are all included in the Oslo micrometastasis study, including 817 patients with known DTC status at time of operation, evaluated by AE immunocytochemical (ICC) staining. The selection of patients were based on available additional samples to perform additional analyses with the following selection criteria: 1) Node negative patients, as AE-based detection for DTC in this group has previously been shown not to be associated with future metastasis and death (except for theT1pN0 non-adjuvant treated subgroup [15]. 2) A selection of node positive patients with a frequency of DTCpositive cases in line with what reported in the original study (approximately $20 \%$, but not included samples with $\geq 3$ DTC by AE staining, because of no available samples for the purpose of this study). 415 patients were enrolled in this study of which 391 cases were evaluable with both methods. The evaluable cohort consisted of 66 node positive, 324 pN0, and one pNX patient (clinically N0). For the statistical analyses, the pNX patient was included in the node negative group. Bone marrow was aspirated bilaterally from both the anterior and posterior iliac crests $(10 \mathrm{ml} / \mathrm{site})$ at the time of primary surgery. From all patients, written informed consent was obtained prior to any study-related procedures. The study was approved by the Regional Ethic Committee in Norway. If indicated adjuvant chemotherapy and/or endocrine therapy (tamoxifen) were administered, according to the national guidelines between 1995 and 1998 [15].

\section{Bone marrow specimen}

The following procedures were accomplished under sterile conditions. Bone marrow aspirates were diluted 1:1 in PBS (1x phosphate buffered saline, Life Technologies, Inc., Roskilde, Denmark) and separated by density centrifugation using Lymphoprep (Nycomed, Oslo, Norway). Mononuclear cells (MNC) were collected from the interphase layer, and washed twice in PBS with 10\% FCS (fetal calf serum; Biological Industries, Kibbutz Beit Haemek, Israel). Direct cytospins were prepared by centrifuging the BM MNC down onto poly-L-lysine coated 
glass slides $\left(0.5 \times 10^{6} \mathrm{MNC} / \mathrm{slide}\right)$ using a Hettich cytocentrifuge (Tutlingen, Germany). The slides were air-dried overnight and stored at $-80^{\circ} \mathrm{C}$ until immunostaining was performed.

\section{Immunocytochemical staining}

In Brief, the A45-B/B3 (AS Diagnostics, Huckeswagen, Germany, www.epimet.de) is a mouse IgG1 monoclonal antibody reactive with a conformational epitope of native cytokeratin heteropolymers $[19,20]$. The recognition of CK8 as part of the heterotypic complex with CK18 has been shown [20]. The two IgG1 mouse monoclonal antibodies AE1 and AE3 (Sanbio, Uden, The Netherlands, www.sanbio.nl) react with acidic and basic keratins respectively, which should cover a spectrum of CKs, including CK10, CK14-16 and CK19 (AE1) and CK 1-8 (AE3) ([21, 22], and J. Huijbregts, Monosan, Sanbio, Uden, The Netherlands; personal communication). For DTC detection, AE1 and AE3 are mixed in a ratio of 1:1. MOPC-21, mouse IgG1 (Sigma Chemical Co., St. Louis, MO, www.sigmaaldrich.com) or mouse anti-FITC monoclonal antibody (IgG1; Micromet, Munich, Germany, www.micromet.de), lacking any known reactivity for epithelial cells or bone marrow cells, was used as isotype specific negative control antibody. For the A45 and the AE protocols the same MOPC-21/FITC concentrations as for the anti-cytokeratin antibodies were used. As positive control to each staining run, either cytospins of the CK-positive breast cancer cell line MCF-7 mixed with the Chinese hamster fibroblast cell line $3 \mathrm{~T} 3$ (A45), or normal BM MNC spiked with MCF-7 cells (AE) were used..

Staining of cytospins with AE antibodies has been performed previously, applying the APAAP method for visualization of antibody-bound cells [14, 15]. For the purpose of this study, additional slides were stained with A45, followed by the APAAP visualization step. The staining protocols have been described previously [12].

In brief, incubation times for $\mathrm{AE}$ and $\mathrm{A} 45$ were $30 \mathrm{~min}$ and $45 \mathrm{~min}$, respectively. As secondary and tertiary antibodies, polyclonal rabbit anti-mouse antibodies ( $\mathrm{Z}$ 259, DAKO, Denmark, www.dako.com), and a mouse monoclonal antibody alkaline phosphatase(AP)-anti-AP (D 651, DAKO, Denmark) were used, respectively. AP-labeled cells were visualized by a red color reaction involving New Fuchsin (Aldrich Chemicals, catalogue no. 229318, 
www.sigmaaldrich.com), naphtol-AS-biphosphate (Sigma, catalogue no. N-2250) and levamisole (Sigma, catalogue no. L-9756). Finally the slides were counterstained with hematoxylin and mounted in Kaiser's glycerine-gelatin (Chroma Gesellschaft Gmbh, Munster, Germany, www.chroma.de). Further staining details are described in the Online Resource. Previously, the specificity of both protocols was proven by analysis of normal bone marrow control samples from 48 healthy donors [12]. Sensitivity and reproducibility of the A45 and AE protocols have been addressed previously $[10,13,14]$.

The double staining procedure is described in the supplementary Online Resource.

\section{DTC detection}

The A45- and AE-stained slides were analyzed by automated screening (10X and 40X magnification) performed by screening systems from Chromavision (ACIS system, San Juan Capistrano, California; used in Hamburg) and Applied Imaging (Ariol system, Applied Imaging, A Genetix Company, New Milton, Great Britain; used in Hamburg and Oslo), respectively. Both systems include an initial, automated screening of the slides, followed by a review procedure during which the investigators (K.E., E.B., and K.P.) morphologically classified the detected elements in a blinded fashion. Detected cells are presented on the screen, but may optionally also be evaluated in the system's microscope using an instant relocation facility. The computerized microscopes have software programs that are optimized for rare cell detection and imaging. The two machines' detection thresholds were adjusted for detection sensitivity at the same level, and comparison between the two systems showed no significant differences. A detailed description of the DTC evaluation is provided in the Online Resource.

\section{Antibody specificity for selected cytokeratins}

The experimental procedures of two-dimensional gel electrophoresis, Western Blot and mass spectrometry are described in Bartkowiak et al. [23], see Online Resource.

\section{Study design and Statistics}

This study was carried out as a retrospective longitudinal observational study of the 391 breast cancer patients evaluated with both markers. Inclusion criteria and 
selection of patients are described in the "Patients" section above. Wherever possible, we have adhered to the REMARK criteria for tumor marker studies as published by McShane et al. [24]. Statistical analyses were carried out based on patient records in the Oslo database. The primary end points were distant disease free survival (DDFS) and breast cancer specific survival (BCSS), measured from the date of bone marrow aspiration at primary surgery to the time of the last follow-up visit, systemic relapse (for DDFS) or death (for BCSS). Median followup were 83 months (range 2-115 months) for time to relapse and 99 months (5118 months) for time to death.

All statistical analyses were conducted with SPSS 15.0 or Stata 9.0, holding a level of significance of 0.05 for every test.

\section{Univariate Analysis}

Differences between clinico-pathologic parameters and DTC status, where one DTC per 2 x $10 \mathrm{e} 6$ analyzed bone marrow mononuclear cells were recorded as positive status, were analyzed by two-sided Chi2 tests (Pearson) or Exact tests (Fisher) and t-tests. Breast cancer specific survival and distant disease-free survival (DDFS) times were calculated and analyzed by Kaplan-Meier curves. Statistically significant outcome differences between patients with DTC and without DTC were identified using log-rank tests.

\section{Multivariate Analysis}

To investigate independent prognostic factors influencing survival and disease progression, multivariate analysis by the Cox Proportional Hazards Model was applied. Important adjusting covariates of prognostic relevance included in this study were: tumor size and grade, nodal status and hormone receptor status. Since the hormone receptor status fails the assumption of proportional hazards in the analysis of DDFS, it was included as a stratification parameter. 


\section{Results}

\section{Specificity of the anti-CK antibodies AE and A45 used for DTC detection}

To investigate the reactivity and specificity of the CK specific antibodies $\mathrm{AE}$ (AE1/AE3) and A45 (A45-B/B3), cell lysate of the basal breast cancer cell line MDA-MB-468 served as a reference protein extract and the cell extract of the luminal breast cancer cell line SKBR3 was used for confirmation. The cell lysates were separated by two-dimensional gel electrophoresis (Online Resource Fig. $1 \& 3)$. The protein identification by mass spectrometry includes the CK that are significant for detection and classification of breast cancer such as CK5, CK7, CK8, CK17, CK18, and CK19 [25, 26] (Online Resource Table 2).

Application of AE to the reference protein extract by 2-DE western blot revealed detection of CK5, CK7, CK8 and CK19, whereas no specific signals were obtained for CK 17 and CK18 (Fig. 1a). Using A45, specific signals for CK7 and CK18 but not for CK5 and CK17 were observed (Fig. 1b); however, weak signals were detected at the coordinates for CK8. Overlay of the X-ray films with the corresponding colloidal Coomassie stained PSQ membranes showed that the signals detected in close proximity to CK19 do not correspond with the CK19 protein spots on the 2-D gels. Therefore, no specific signals were detected by A45 for CK19.

\section{Patient and DTC detection characteristics}

Of the samples available for this study, a total of 391 patients had evaluable DTC results for both the A45 and AE protocols. Median patient age was 58 years (range: 27-87). There was no statistical difference in median age between the bone marrow-positive and bone marrow-negative group (t-test, $\mathrm{p}=0.106$; data not shown). The node negative patients had smaller primary tumours (72\% pT1, 25\% pT2, 1\% pT3, 2\% unknown) than the node positive patients (49\% pT1 tumours, $27 \%$ pT2 and 18\% pT3 (6\% unknown)). Thirty-one percent (122/391) of all patients received adjuvant systemic treatment ( $21 \%$ of node negative, $89 \%$ of node positive patients), including endocrine therapy and/or chemotherapy, $27 \%$ 
(100/391) received hormonal therapy, and 10\% (38/391) were under a combined regimen of chemotherapy plus tamoxifen (data not shown).

The A45 and the AE staining from the 66 node positive cases were scored by both participating institutions and the two independent scorings ("Oslo" and "Hamburg") were compared. The rates of positivity for AE and for A45 were correspondent: By both scorings $12.1 \%$ (8/66) of the patients had DTC detected by A45 and 19.7\% (13/66) by AE (Online Resource Table 1). Inter-observer comparisons did not show identical results, but highly significant correlations between Oslo and Hamburg scorings for both staining protocols; a 93.9\% $(\mathrm{p}<0.001)$ and $97.0 \%(\mathrm{p}<0.001)$ congruence in results for A45 and AE, respectively. The results support that an overall comparison of the A45 and AE staining results could be achieved by using one scoring only which here is the Oslo scoring.

Analysing all the patient samples, numbers of detected DTC ranged from 1 to 5 per $2 \times 10^{6}$ mononuclear cells (MNC) analyzed and were not statistically different between the two antibodies. Considering all the included cases, 6.1\% (24/391) had A45-positive DTC in bone marrow and 10.5\% (41/391) had AE-positive DTC (Table 1). Overall, 16.1\% (63/391) of the patients had DTC in the bone marrow (AE and A45 in combination). Congruence in results between the two antibodies was high (84.4\%), but the concordance was only 3.2\% (2/63) within DTC-positive bone marrows (Table 1). No statistical correlation between A45 and AE was found ( $\mathrm{p}=1.000)$. For the subgroup of node negative patients, $4.9 \%(16 / 325)$ of the bone marrows were positive for A45 and 8.6\% (28/325) for AE (Table 2), and there was no overlap between the positive cases. By combined analysis of $\mathrm{AE}$ and A45, 13.5\% (44/325) were DTC-positive (data not shown). Within the node positive subgroup, $12.1 \%$ (8/66) patients had DTC detected by A45, and $19.7 \%$ (13/66) by AE. Two patients had overlapping DTC results by A45 and AE. Numbers of detected DTC ranged from 1 to 4 per $2 \times 10^{6} \mathrm{MNC}$ in the node negative, and from 1 to 5 cells per $2 \times 10^{6} \mathrm{MNC}$ in the node positive subgroup. Tumor cell numbers were not statistically different for A45 and AE.

The different CK patterns recognized by the antibodies and the small overlap of AE-positive and A45-positive cases directed us to the question whether AE and 
A45 detect different subpopulations of DTC in vivo. Immunocytochemical double staining (i.e., AE and A45 were applied to the same slide) revealed subsets of DTC labeled with both antibodies but also DTC exclusively stained with either A45 or AE (Fig.3).

\section{Histopathological correlations}

The occurrence of DTC was correlated to primary tumor characteristics. A significant association between the antibodies and the nodal status was observed for AE ( $\mathrm{p}=0.019)$, for A45 ( $\mathrm{p}=0.036$; Table 2$)$ and for both antibodies combined ( $\mathrm{p}=0.003$; data not shown). An increased number of DTC-positive bone marrows were detected by $\mathrm{AE}$ in hormone receptor (HR)-negative versus HR-positive cases ( $\mathrm{p}=0.006)$. In contrast, all but one patients with DTC detected by A45 (23/24) were HR-positive ( $\mathrm{p}=0.061$ ). Higher DTC detection rates with increasing T-status were indicated for $\operatorname{AE~}(\mathrm{p}=0.056)$ and for both antibodies combined $(\mathrm{p}=0.016$; data not shown; for $\mathrm{A} 45, \mathrm{p}=0.365$ ). Other parameters were not significantly different between DTC-positive and DTC-negative patients for either staining protocol (Table 2).

\section{Survival analysis}

During the observation period, 67/391 patients (17.1\%) died, of those 43 patients of breast cancer. There were 57/391 patients (14.6\%) who suffered from systemic relapse during follow-up. In total, $24.6 \%$ of patients who relapsed had DTC in their bone marrow detected by either $\mathrm{AE}$ and/or A45, whereas only $14.8 \%$ of the relapse-free patients harbored DTC ( $\mathrm{p}=0.065$; Fisher's exact test). DTC detected by A45 alone were found significantly more frequent in patients who suffered from relapse than in relapse-free patients $(\mathrm{p}=0.039$; Table 2$)$.

The Kaplan Meier survival plots for the entire cohort of 391 patients, according to the A45 and AE staining, are presented in Fig. 2a. In contrast to $\mathrm{AE}(\mathrm{p}=0.487)$, univariate analysis (log-rank test) revealed that DDFS was associated with the presence of A45-detected DTC as compared with their absence ( $\mathrm{p}=0.023)$. BCSS did not significantly correlate to DTC status. 
Within the node positive cohort (Fig. 2b), the presence of DTC detected by AE alone ( $\mathrm{p}=0.036)$ or by the combination of $\mathrm{A} 45$ and/or $\mathrm{AE}(\mathrm{p}=0.044)$ was correlated to reduced BCSS. This was not observed for A45 alone $(\mathrm{p}=0.151)$. Within the subgroup of node negative patients, no significant association between presence of DTC and survival was observed (Fig. 2c). For A45-positive patients an insignificant trend towards higher risk of early systemic recurrence compared to A45-negative patients was indicated ( $\mathrm{p}=0.108$; Fig. 2c).

\section{Multivariate analysis}

Multivariate Cox regression analysis $(\mathrm{n}=355)$ included DTC status by A45 and by $\mathrm{AE}$, adjusting for tumor size, nodal status, hormone receptor status and tumor grade. Presence of DTC detected by A45 was an independent significant prognostic factor for DDFS (HR 2.2; 95\%CI:[1.05; 4,53]; $\mathrm{p}=0.036$; Table 3). Tumor grade was a strong prognostic factor for both BCSS and DDFS, whereas tumor size was related to DDFS and nodal status to BCSS. The Cox proportional hazards regression analysis for DDFS had to be stratified by the hormone receptor status because the model requirements are not met. In that case, it is not possible to estimate a constant hazard ratio for hormone receptor status. The results were not significantly altered when treatment status was included in the analyses. Taken into account the type of systemic therapy administered (tamoxifen only, chemotherapy and tamoxifen, chemotherapy alone), no interactions between the results obtained with $\mathrm{A} 45$ or $\mathrm{AE}$ and either therapy regimen were revealed (data not shown). 


\section{Discussion}

This study describes, for the first time, the parallel assessment of the two pan antiCK antibodies most frequently used for DTC detection. Our results revealed that these antibodies appear to identify different populations of DTC, depending on the primary tumor biology and disease stage, with important implications for their clinical utility.

The DTC detection rate in the present study was low. Each antibody by itself resulted in $6.2 \%$ (A45) and $10.5 \%$ (AE) positivity. Main reason for the low positivity rates may be the very favorable clinical characteristics of the investigated patient cohort with more than $80 \%$ pN0 cases and over $68 \% \mathrm{~T} 1$ tumors. This consideration is supported by the finding that the detection rates within the node positive subgroup were higher for both antibodies, with $12.1 \%$ for A45 and $19.7 \%$ for AE. However, other explanations for the low overall detection rate and the difference in A45 and AE1 staining results may potentially include other (yet unknown) methodological issues as well as Poisson distribution of rare events, which may affect the reproducibility of the results independent of the antibody applied. In our study, as well as in other reports with a fairly low DTC detection rate, a standardized and careful cell evaluation was performed, which excludes occasional ICC positive cells with hematopoietic cell-compatible cell morphology as DTC. Such stained cells with hematopoetic cell characteristics have been shown to lack prognostic significance [27]. Other groups reported higher incidences of DTC in bone marrow but with less stringent criteria for DTC positivity [28-30].

The Oslo group has previously reported lower DTC prevalence than the Hamburg group [13-15]. However, comparing the DTC scorings by the two centers in the present study, only minor differences were revealed. The satisfactory correlation supported the use of one scoring for the comparison of AE- and A45-based DTC detection and correlation to clinical outcome. Both antibodies are well-established and have been recommended for DTC detection in bone marrow in a consensus paper by German, Austrian and Swiss societies of senology [9].

We found that only a small percentage of all positive cases were detected by A45 and AE in parallel. The most striking difference seems to appear between 
the hormone receptor positive and negative patients. Histopathological correlation shows that A45 primarily detected DTC in HR-positive patients, while AE detected DTC in relatively high frequency in HR-negative patients. This observation can be explained by a different $\mathrm{CK}$ expression pattern in HR-positive and HR-negative primary tumors, with up-regulation of CK8, 18 and 19 in HRpositive tumors and down-regulation of CK5-7 and CK14-17, as compared to HRnegative [31]. As indicated by our present proteomics analysis, A45 primarily detected CK7 and CK18, which could explain the more selective detection of DTC in patients with HR-positive tumors. In contrast, in addition to CK8 and CK19, AE detected CK5 and 7 - the latter two mainly detected in tumor cells of HR-negative patients.

To identify the anti-CK antibody specificities, we have applied an extremely reliable and highly accurate proteomic approach [23]. The well characterized cell extract of the basal breast cancer cell line, MDA-MB-468, served as a reference protein mixture and the cell extract of the luminal breast cancer cell line, SKBR3, was used for confirmation. These cell lines express all of the common CK proteins known to play a role in breast cancer and therefore provide a sufficient basis to profile the reaction pattern of the anti-CK antibodies used in our study.

Most importantly, the present study shows differences in the prognostic information obtained if AE and A45 are applied for DTC detection. Analysis of our 391 patients (83\% node negative and $17 \%$ node positive) confirms that the presence of A45-detected DTC in bone marrow predicts systemic relapse, and is an independent prognostic factor (Cox multivariate analysis). A trend for reduced DDFS by A45 was also observed for the node negative subgroup (Fig. 2b, $\mathrm{p}=0.108$ ). This was not the case for AE. However, for the node positive subgroup, the opposite result was obtained, AE-based DTC status (Fig. 2a, p=0.036) correlated to survival whereas A45 did not. The difference between the node negative and node positive cohort also explains why the combined results of $\mathrm{AE}$ and A45 did not result in increased prognostic information. These results indicate that the CK expression pattern in DTC (and hence the difference in A45 and AE staining) may vary during the natural course of the disease; an assumption supported by previous reports on down-regulation of CK proteins during breast cancer progression $[16,17]$. Our A45-AE-double staining experiment furthermore 
supports the assumption that CK expression is heterogeneous in DTC. Korsching et al. reported $[32,33]$ that up-regulation of CK5 (detected by AE only and missed by A45) goes along with a progenitor cell and therefore more aggressive DTC phenotype and disease progression. This might explain why DTC detected by AE acquired prognostic significance in the subgroup of node positive, i.e. more advanced patients. However, it is conceivable that CK5-expressing DTC might also be present in lymph node negative patients but maybe at a lower frequency, which could be one explanation for the different prognostic information between the nodal subgroups. Furthermore, as these analyses are retrospective, additional studies would be needed before drawing definite conclusions.

This study has implications for future studies using DTC analysis for risk assessment and therapy monitoring in breast cancer patients, and the implications are also applicable to the detection of circulating tumor cells in the peripheral blood of cancer patients [3]. The findings underlie the unmet need for a detailed knowledge of the staining patterns for "broad spectrum" CK antibodies. This knowledge is important for both interpretation of the results of previously published DTC studies and selection of the most optimal antibody or combination of antibodies to be used in future DTC studies. Information of differences in expression patterns of the DTC marker genes within subgroups of breast cancer [34] will be important for further optimization of DTC detection. This will be of particular importance in the context of EMT and cancer stem cell properties [4, 35 ] and might affect future strategies for the detection of disseminating tumor cells in the bone marrow and peripheral blood. 
Acknowledgements

We thank Sonja Santjer, Cornelia Coith, Antje Andreas and Sandra Schwentesius for their excellent technical assistance. The study was funded by the DISMAL project by the European Commission (contract no. LSHC-CT-2005-018911), Norwegian Cancer Society and Margaret Solbergs Legacy.

\section{References}

Pantel K, Cote RJ, Fodstad O (1999) Detection and clinical importance of micrometastatic disease. J Natl Cancer Inst 91:1113-1124.

Gnant M, Mlineritsch B, Schippinger W, et al. (2009) Endocrine therapy plus zoledronic acid in premenopausal breast cancer. N Engl J Med 360:679-691.

Scher HI, Pantel K (2009) Bone marrow aspiration for disseminated tumor cell detection: a musthave test or is the jury still out? J Clin Oncol 27:1531-1533.

Pantel K, Brakenhoff RH, Brandt B (2008) Detection, clinical relevance and specific biological properties of disseminating tumour cells. Nat Rev Cancer 8:329-340.

Brugger W, Bross KJ, Glatt M, et al. (1994) Mobilization of tumor cells and hematopoietic progenitor cells into peripheral blood of patients with solid tumors. Blood 83:636-640.

Bidard FC, Vincent-Salomon A, Gomme S, et al. (2008) Disseminated tumor cells of breast cancer patients: a strong prognostic factor for distant and local relapse. Clin Cancer Res 14:3306-3311. Zhang XH, Wang Q, Gerald W, et al. (2009) Latent bone metastasis in breast cancer tied to Srcdependent survival signals. Cancer Cell 16:67-78.

Borgen E, Naume B, Nesland JM, et al. (1999) Standardization of the immunocytochemical detection of cancer cells in BM and blood: I. establishment of objective criteria for the evaluation of immunostained cells. Cytotherapy 1:377-388.

Fehm T, Braun S, Muller V, et al. (2006) A concept for the standardized detection of disseminated tumor cells in bone marrow from patients with primary breast cancer and its clinical implementation. Cancer 107:885-892.

Pantel K, Schlimok G, Angstwurm M, et al. (1994) Methodological analysis of immunocytochemical screening for disseminated epithelial tumor cells in bone marrow. $\mathbf{J}$ Hematother 3:165-173.

Fuchs E, Weber K (1994) Intermediate filaments: structure, dynamics, function, and disease. Annu Rev Biochem 63:345-382.

Borgen E, Pantel K, Schlimok G, et al. (2006) A European interlaboratory testing of three wellknown procedures for immunocytochemical detection of epithelial cells in bone marrow. Results from analysis of normal bone marrow. Cytometry B Clin Cytom 70:400-409.

Braun S, Pantel K, Muller P, et al. (2000) Cytokeratin-positive cells in the bone marrow and survival of patients with stage I, II, or III breast cancer. N Engl J Med 342:525-533.

Naume B, Borgen E, Kvalheim G, et al. (2001) Detection of isolated tumor cells in bone marrow in early-stage breast carcinoma patients: comparison with preoperative clinical parameters and primary tumor characteristics. Clin Cancer Res 7:4122-4129.

Wiedswang G, Borgen E, Karesen R, et al. (2003) Detection of isolated tumor cells in bone marrow is an independent prognostic factor in breast cancer. J Clin Oncol 21:3469-3478. Willipinski-Stapelfeldt B, Riethdorf S, Assmann V, et al. (2005) Changes in cytoskeletal protein composition indicative of an epithelial-mesenchymal transition in human micrometastatic and primary breast carcinoma cells. Clin Cancer Res 11:8006-8014.

Woelfle U, Sauter G, Santjer S, et al. (2004) Down-regulated expression of cytokeratin 18 promotes progression of human breast cancer. Clin Cancer Res 10:2670-2674.

Mani SA, Guo W, Liao MJ, et al. (2008) The epithelial-mesenchymal transition generates cells with properties of stem cells. Cell 133:704-715.

Kasper M, Stosiek P, Typlt H, et al. (1987) Histological evaluation of three new monoclonal anticytokeratin antibodies. 1. Normal tissues. Eur J Cancer Clin Oncol 23:137-147. 
Waseem A, Karsten U, Leigh IM, et al. (2004) Conformational changes in the rod domain of human keratin 8 following heterotypic association with keratin 18 and its implication for filament stability. Biochemistry 43:1283-1295.

Woodcock-Mitchell J, Eichner R, Nelson WG, et al. (1982) Immunolocalization of keratin polypeptides in human epidermis using monoclonal antibodies. J Cell Biol 95:580-588.

Sun TT, Tseng SC, Huang AJ, et al. (1985) Monoclonal antibody studies of mammalian epithelial keratins: a review. Ann N Y Acad Sci 455:307-329.

Bartkowiak K, Wieczorek M, Buck F, et al. (2009) Two-dimensional differential gel electrophoresis of a cell line derived from a breast cancer micrometastasis revealed a stem/ progenitor cell protein profile. J Proteome Res 8:2004-2014.

McShane LM, Altman DG, Sauerbrei W, et al. (2005) Reporting recommendations for tumor marker prognostic studies. J Clin Oncol 23:9067-9072.

Abd El-Rehim DM, Pinder SE, Paish CE, et al. (2004) Expression of luminal and basal cytokeratins in human breast carcinoma. J Pathol 203:661-671.

van de Rijn M, Perou CM, Tibshirani R, et al. (2002) Expression of cytokeratins 17 and 5 identifies a group of breast carcinomas with poor clinical outcome. Am J Pathol 161:1991-1996. Naume B, Wiedswang G, Borgen E, et al. (2004) The prognostic value of isolated tumor cells in bone marrow in breast cancer patients: evaluation of morphological categories and the number of clinically significant cells. Clin Cancer Res 10:3091-3097.

Braun S, Vogl FD, Naume B, et al. (2005) A pooled analysis of bone marrow micrometastasis in breast cancer. N Engl J Med 353:793-802.

Schindlbeck C, Kampik T, Janni W, et al. (2005) Prognostic relevance of disseminated tumor cells in the bone marrow and biological factors of 265 primary breast carcinomas. Breast Cancer Res 7:R1174-1185.

Slade MJ, Singh A, Smith BM, et al. (2005) Persistence of bone marrow micrometastases in patients receiving adjuvant therapy for breast cancer: results at 4 years. Int J Cancer 114:94-100. van de Vijver MJ, He YD, van't Veer LJ, et al. (2002) A gene-expression signature as a predictor of survival in breast cancer. N Engl J Med 347:1999-2009.

Korsching E, Packeisen J, Agelopoulos K, et al. (2002) Cytogenetic alterations and cytokeratin expression patterns in breast cancer: integrating a new model of breast differentiation into cytogenetic pathways of breast carcinogenesis. Lab Invest 82:1525-1533.

Korsching E, Packeisen J, Helms MW, et al. (2004) Deciphering a subgroup of breast carcinomas with putative progression of grade during carcinogenesis revealed by comparative genomic hybridisation (CGH) and immunohistochemistry. Br J Cancer 90:1422-1428.

Naume B., Zhao X., Synnestvedt M., et al. (2007) Presence of bone marrow micrometastasis is associated with different recurrence risk within molecular subtypes of breast cancer. Molecular Oncology 1:160-171.

Polyak K, Weinberg RA (2009) Transitions between epithelial and mesenchymal states: acquisition of malignant and stem cell traits. Nat Rev Cancer 9:265-273. 


\section{Tables}

Table 1 Cross table of disseminated tumor cell status in breast cancer patients $(n=391)$ as defined by staining with $\mathrm{AE}$ and $\mathrm{A} 45$ antibodies.

\begin{tabular}{|l|c|c|c|}
\hline & AE negative & AE positive & Total \\
\hline \multirow{2}{*}{ A45 negative } & 328 & 39 & 367 \\
& $83.9 \%$ & $10.0 \%$ & $93.9 \%$ \\
\hline \multirow{2}{*}{ A45 positive } & 22 & 2 & 24 \\
& $5.6 \%$ & $0.5 \%$ & $6.1 \%$ \\
\hline \multirow{2}{*}{ Total } & 350 & 41 & 391 \\
& $89.5 \%$ & $10.5 \%$ & $100.0 \%$ \\
\hline
\end{tabular}


Table 2 Prevalence of disseminated tumor cells in bone marrow according to histopathological parameters and recurrence status.

\begin{tabular}{|c|c|c|c|c|c|}
\hline Characteristic & $\begin{array}{c}\text { Total } \\
\text { number of } \\
\text { patients }\end{array}$ & $\begin{array}{c}\text { Number of } \\
\text { A45-B/B } \\
\text { positive (\%) }\end{array}$ & p-value & $\begin{array}{c}\text { Number of } \\
\text { AE1/AE3 } \\
\text { positive (\%) }\end{array}$ & p-value \\
\hline All & 391 & $24(6.1 \%)$ & & $41(10.5 \%)$ & \\
\hline $\begin{array}{l}\text { Tumor Status } \\
\text { T1 } \\
\text { T2 } \\
\text { T3 } \\
\text { T missing } \\
\end{array}$ & $\begin{array}{c}267 \\
99 \\
14 \\
11\end{array}$ & $\begin{array}{r}16(6.0 \%) \\
6(6.1 \%) \\
2(14.3 \%) \\
0 \\
\end{array}$ & 0.365 & $\begin{array}{c}27(10.1 \%) \\
7(7.1 \%) \\
4(28.6 \%) \\
3 \\
\end{array}$ & $0.056^{c}$ \\
\hline $\begin{array}{l}\text { Nodal Status } \\
\text { N0 } \\
\text { N1 } \\
\text { N2 } \\
\text { N3 } \\
\text { Missing } \\
\end{array}$ & $\begin{array}{c}325 \\
43 \\
17 \\
6 \\
0 \\
\end{array}$ & $\begin{array}{c}16(4.9 \%) \\
4(9.3 \%) \\
3(17.6 \%) \\
1(16.7 \%) \\
0\end{array}$ & $0.036^{b}$ & $\begin{array}{l}28(8.6 \%) \\
7(16.3 \%) \\
4(23.5 \%) \\
2(33.3 \%) \\
0\end{array}$ & $0.019^{b}$ \\
\hline $\begin{array}{l}\text { Tumor Grade } \\
1 \\
2 \\
3 \\
\text { Grade missing }\end{array}$ & $\begin{array}{c}110 \\
184 \\
88 \\
9\end{array}$ & $\begin{array}{c}5(4.5 \%) \\
14(7.6 \%) \\
5(5.7 \%) \\
0\end{array}$ & 0.558 & $\begin{array}{c}13(11.8 \%) \\
13(7.1 \%) \\
14(15.9 \%) \\
1\end{array}$ & 0.072 \\
\hline $\begin{array}{l}\text { HR Status }^{a} \\
\text { HR positive } \\
\text { HR negative } \\
\text { HR missing }\end{array}$ & $\begin{array}{c}300 \\
75 \\
16 \\
\end{array}$ & $\begin{array}{c}23(7.7 \%) \\
1(1.3 \%) \\
0 \\
\end{array}$ & $0.061^{c}$ & $\begin{array}{c}24(8.0 \%) \\
14(18.7 \%) \\
3\end{array}$ & $0.006^{b}$ \\
\hline $\begin{array}{l}\text { Her2/neu by IHC } \\
\text { Her2 negative } \\
\text { Her2 positive } \\
\text { Missing }\end{array}$ & $\begin{array}{c}315 \\
16 \\
60 \\
\end{array}$ & $\begin{array}{c}23(7.3 \%) \\
0 \\
1\end{array}$ & 0.614 & $\begin{array}{c}30(9.5 \%) \\
3(18.8 \%) \\
8\end{array}$ & 0.206 \\
\hline $\begin{array}{l}\text { Histology } \\
\text { Ductal } \\
\text { Lobular } \\
\text { Missing }\end{array}$ & $\begin{array}{c}303 \\
66 \\
22\end{array}$ & $\begin{array}{c}17(5.6 \%) \\
6(9.1 \%) \\
1\end{array}$ & 0.289 & $\begin{array}{c}33(10.9 \%) \\
7(10.6 \%) \\
1\end{array}$ & 0.946 \\
\hline $\begin{array}{l}\text { Vascular Invasion } \\
\text { No } \\
\text { Yes } \\
\text { Missing }\end{array}$ & $\begin{array}{c}306 \\
48 \\
37 \\
\end{array}$ & $\begin{array}{c}16(5.2 \%) \\
5(10.4 \%) \\
3\end{array}$ & 0.157 & $\begin{array}{c}28(9.2 \%) \\
4(8.3 \%) \\
9 \\
\end{array}$ & 1.000 \\
\hline $\begin{array}{l}\text { Systemic recurrenc } \\
\text { No } \\
\text { Yes } \\
\text { Missing }\end{array}$ & $\begin{array}{c}331 \\
57 \\
3\end{array}$ & $\begin{array}{c}17(5.1 \%) \\
7(12.3 \%) \\
0\end{array}$ & $0.039^{b}$ & $\begin{array}{c}33(10.0 \%) \\
8(14.0 \%) \\
0\end{array}$ & 0.356 \\
\hline
\end{tabular}

${ }^{a}$ HR Status, hormone receptor status includes estrogen and/or progesterone receptors; ${ }^{b}$ Statistical significance; ${ }^{c}$ Borderline significance. 
Table 3 Multivariate Cox regression analysis for DDFS and BCSS including relevant clinical variables. P, p-value; HR, Hazard ratio; CI, Confidence interval; DDFS, Relapse free survival ( $\mathrm{n}=351)$; BCSS, Breast cancer specific survival $(\mathrm{n}=355)$.

\begin{tabular}{|l|c|c|c|c|c|c|}
\hline \multirow{2}{*}{ Characteristic } & \multicolumn{3}{|c|}{ DDFS } & \multicolumn{3}{c|}{ BCSS } \\
\cline { 2 - 7 } & $\mathbf{P}$ & HR & Cl & P & HR & CI \\
\hline Tumor Size (pT1vspT2/3) & 0.045 & 1.7 & $1.01-2.68$ & 0.085 & 1.8 & $0.92-3.43$ \\
\hline Nodal Status (pN0vspN1-3) & 0.062 & 1.7 & $0.97-3.02$ & $<0.001$ & 3.6 & $1.81-7.22$ \\
\hline Tumor Grade (G1/2vsG3) & $<0.001$ & 0.2 & $0.07-0.43$ & 0.003 & 0.1 & $0.02-0.46$ \\
\hline Tumor Grade (G1vsG2/3) & 0.005 & 0.5 & $0.25-0.79$ & 0.001 & 0.3 & $0.13-0.59$ \\
\hline Hormone Receptor (pos/neg) & n.i. $^{2}$ & n.i. & n.i. & 0.243 & 0.6 & $0.31-1.35$ \\
\hline DTC (A45) & 0.036 & 2.2 & $1.05-4.53$ & 0.971 & 1.0 & $0.30-3.49$ \\
\hline DTC (AE) & 0.493 & 0.7 & $0.31-1.75$ & 0.981 & 1.0 & $0.38-2.60$ \\
\hline
\end{tabular}

${ }^{a}$ n.i., Hormone Receptor status not included; the hazard ratios for the other variables in the stratified Cox-Model are estimated adjusted for hormone receptor status. Because the covariate 'Hormone Receptor' does not meet the requirement of proportional hazards, a multivariate Cox regression stratified by this factor was performed. 


\section{Figures}

Fig. 12 -DE western blot of MDA-MB-468 cell lysate on linear $\mathrm{pH}$ gradients $(13 \mathrm{~cm})$. Left panels: $\mathrm{pH}$ gradient 4-7; right panels $\mathrm{pH}$ gradient 6-11. Detection of CKs using the primary antibodies AE1/AE3 (a) and A45-B/B3 (b). Spots that have been assigned to identified CK species by mass spectrometry (see Online Resource) are denoted with arrows; (1) CK5; (2) CK7; (3) CK8; (4) CK17; (5) CK18; (6) CK19 (Online Resource Table 2). Due to limited representation of very alkaline proteins on 2-D gels western blots have been restricted to a maximum isoelectric point of approximately 9.4. The horizontal spot trains observed between an isoelectric point of 6 and 8.2 might be a result of post-translational modification of CK5. Each 2-DE was performed in three independent experiments.

Fig. 2 Kaplan-Meier curve for DDFS (upper row) and BCSS (bottom row) related to DTC status (a) in all patients ( $\mathrm{n}=391)$, (b) in node-positive patients $(\mathrm{n}=66)$, and (c) in node-negative patients ( $\mathrm{n}=325$ ), for A45 (left), for AE (center), and for A45 and AE combined analysis (right). Green lines indicate DTC-positive cases, blue lines DTC-negative cases.

Fig. 3 Bone marrow sample of a breast cancer patient double-stained with AE coupled to Alexa 488 (green) and A45 directly conjugated with $\mathrm{Cy} 3$ (red). Images were taken with the Ariol ${ }^{\mathrm{TM}}$ system (Applied Imaging, A Genetix Company, New Milton, Great Britain). 
Figure 1a.

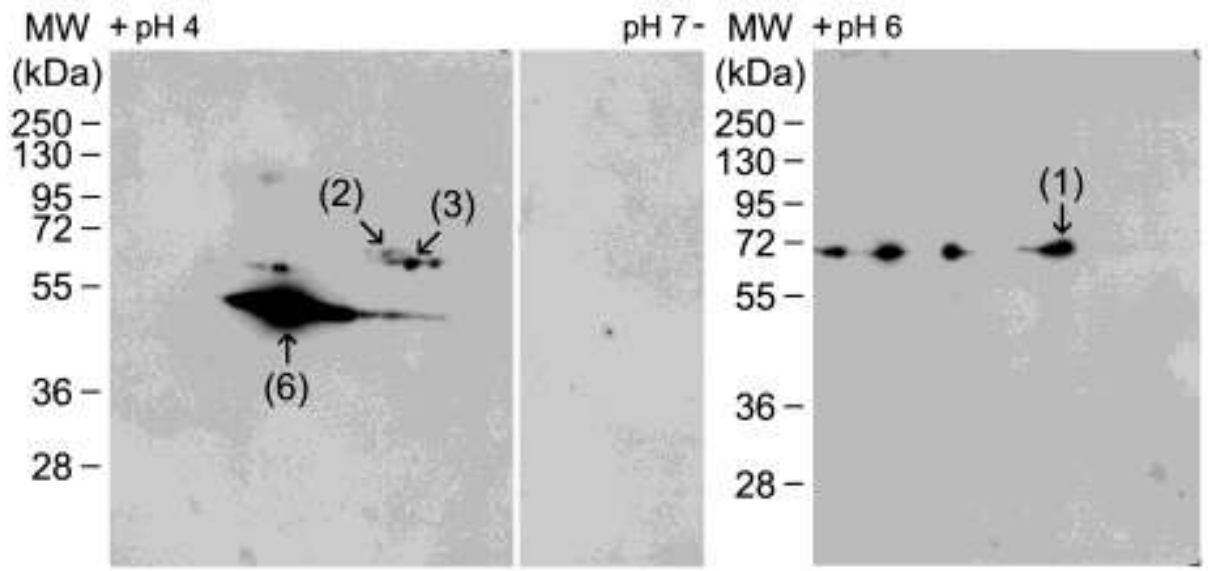

pH 11 -

Figure $1 \mathrm{~b}$.

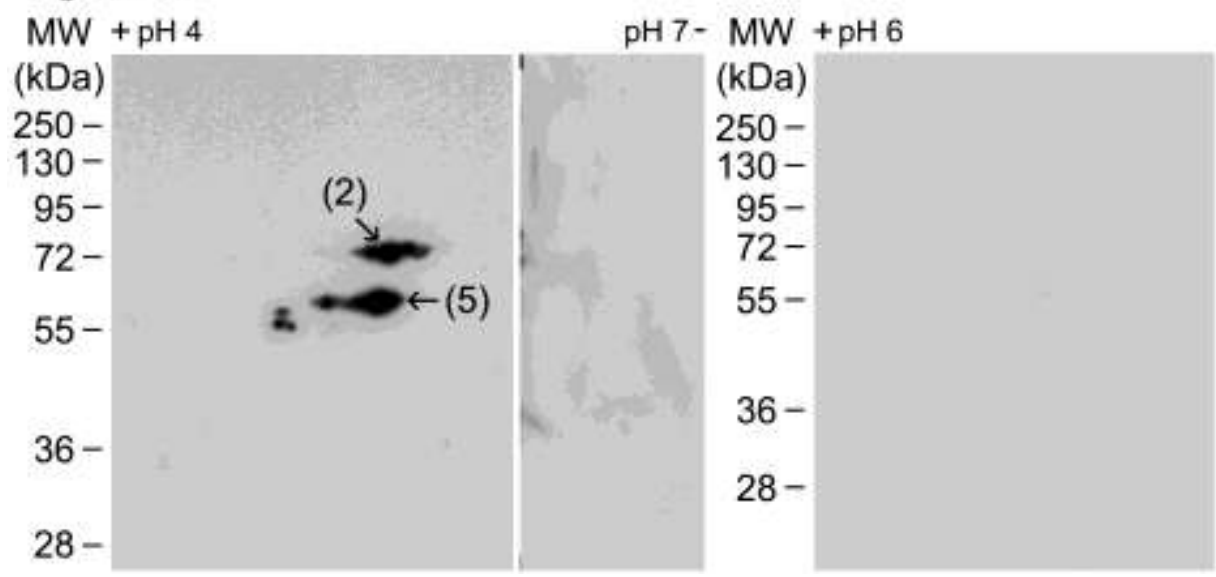

$\mathrm{pH} 11$ - 
Figure 2a.

DDFS

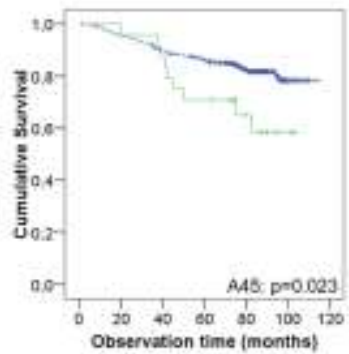

BCSS

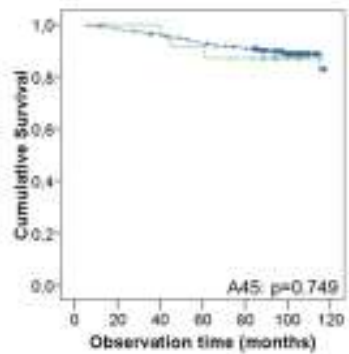

Figure $2 b$.

DDFS

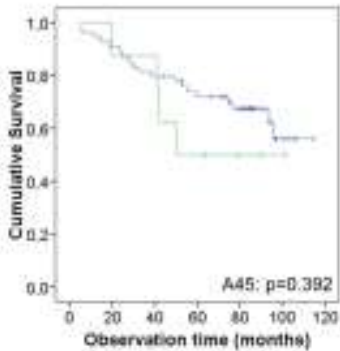

BCss

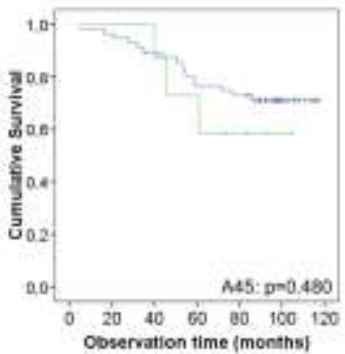

Figure 2c.
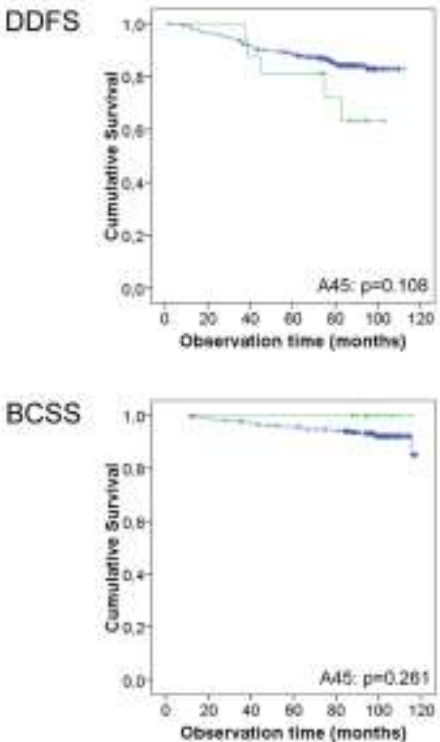
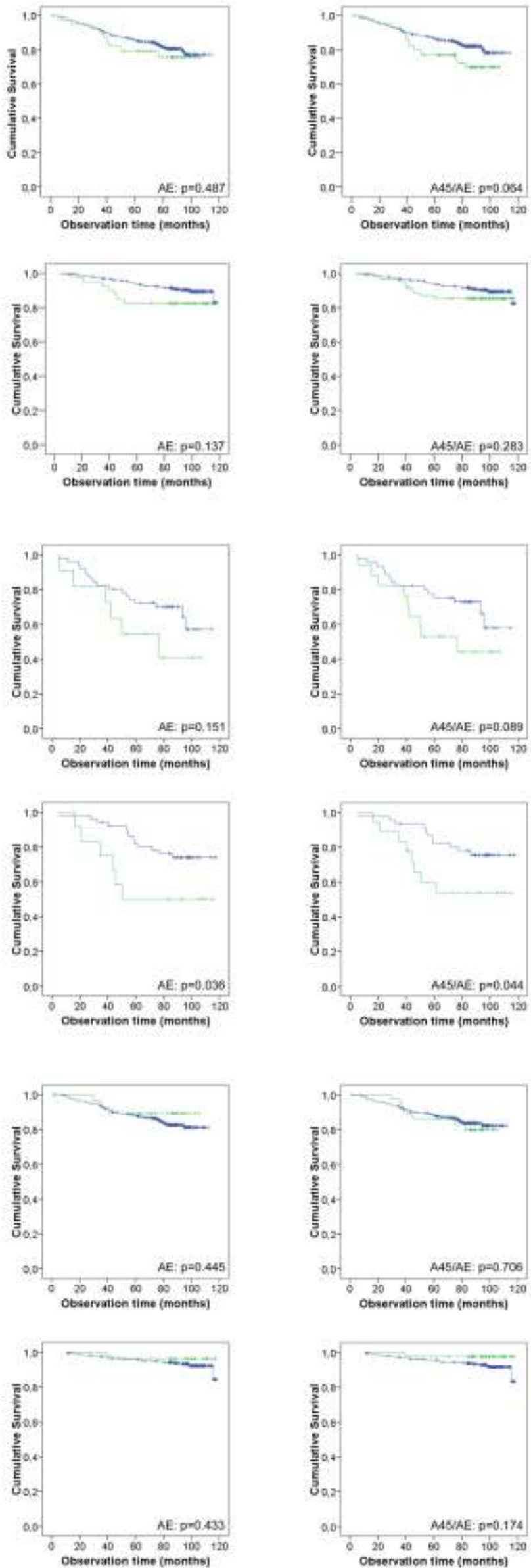
Figure 3.

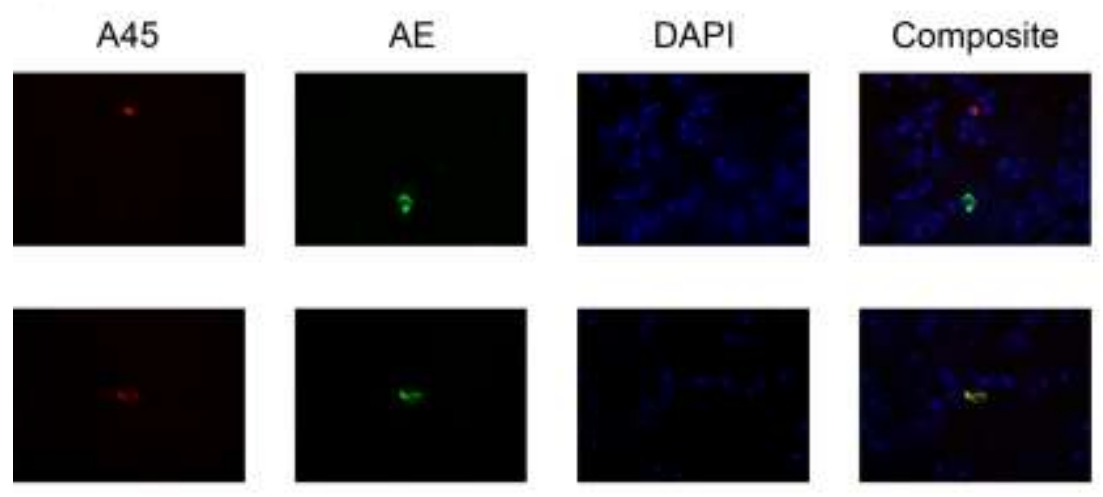

